\title{
Prevalence of Refractive Errors in Children 6 - 9 Years
}

\author{
Eglantina Molosiu', Sulejman Zhugli ${ }^{2}$ \\ ${ }^{1}$ Regional Hospital of Fier, Albania \\ ${ }^{2}$ University Hospital Center "Mother Theresa", Tirana, Albania
}

\begin{abstract}
The investigation of the prevalence and causes of visual impairment allow the planning of preventive ophthalmologic programs, providing more precise interventions directed to the preservation of ocular health. The aim of the stydy was to estimate the prevalence of myopia, hyperopia and astigmatism in schoolchildren ranging from 6 to 9 years of age. In this cross-sectional study in children 3-9 years of age in Fier, Albania in the 2011-2012 school year, cluster sampling was performed during March and April 2012. 192 (8.7\%) schoolchildren had uncorrected visual acuity 20/40 or worse in the better eye.Visual impairment is a common disorder in schoolaged children. They can be easily diagnosed, measured, and corrected with spectacles and other refractive corrections to obtain normal vision.
\end{abstract}

Keywords: Anisometropic amblyopia, treatment, children, examination

\section{Introduction}

The implementation of programs for the prevention of blindness has been widely recommended by the World Health Organization (WHO) since the 70s $(1,2)$. Among the most important factors to be considered regarding prevention of blindness are the ophthalmologic disorders occurring at school age. However, in developing countries, preventive programs are not privileged, probably due to the limitation of available resources in the health area and to the lack of emphasis on health action $(3,4)$. This would in part explain why the prevalence of severe visual deficiency is 10 to 40 times higher in certain areas of developing countries when compared with industrialized countries (5).

The investigation of the prevalence and causes of visual impairment allow the planning of preventive ophthalmologic programs, providing more precise interventions directed to the preservation of ocular health (6.7). The purpose of sanitary ophthalmology includes the prevention or attenuation of ophthalmologic diseases or disorders, their complications and consequences, the promotion of conditions for the preservation of normal vision, and the recovery of health through collective measures, motivating the population, but using the community's own resources (8).

According to studies, the greatest obstacle to preventive measures is not the lack of adequate technology, but the inability to create favorable conditions to motivate the population, to organize and to facilitate the access to ophthalmologic assistance (9).

Projects aiming at the improvement of vision in children at school age received special attention in the 70 s, considering the influence of poor visual performance on the teachinglearning process and on the normal development of the child $(1,10)$.

The improvement in vision screening performed by adequately trained and supervised nonmedical personnel allowed the identification of the prevalence of visual deficiency among preschool and schoolchildren (11). The application of simple vision tests, and the observation of ocular signs and symptoms which are indicative of disorders by teachers, was shown to be efficient (12), making the early identification of functional and organic diseases in this population possible. It is also known that early detection of ocular problems in children, such as refractive errors, strabismus, and chronic infections prevents the establishment of permanent damage to visual acuity and binocular vision $(13,14)$. Recently, a significant increase in the prevalance of myopia has been noted. This trend is most probably due to the occurrence of civilizational changes such as the increase in intensive near work - reading, writing and working on a computer (15). The occurrence of hyperopia among children, however decreases with age. Children are born with physiological hyperopia. In the course of time, the optical components in the eyeball change, and hyperopia gradually decreases (16). Prevalence of astigmatism among schoolchildren remains at the same level of a few per cent (17). The existence of a growing demand for different clinical studies dealing with the development of the eye is based on the increasing use of contact lenses and the performance of corneal refractive surgeries, as well as intraocular lens applications at the time being. The aim of the stydy was to estimate the prevalence of myopia, hyperopia and astigmatism in schoolchildren ranging from 6 to 9 years of age.

\section{Material and Methods}

In this cross-sectional study in children 3-9 years of age in Fier, Albania in the 2011-2012 school year, cluster sampling was performed during March and April 2012.

Study population and sample

Fier, is a city in southwest Albania. The population is approximately 57198 (census 2011). The study population numbered 11 114. Sampling was performed with a random cluster approach, with 75 schools and 111 children garden representing clusters. A total of 2244 children were enrolled after the random selection of 6 schools and 14 children garden. The sample size for each grade level, according to 


\section{International Journal of Science and Research (IJSR) \\ ISSN (Online): 2319-7064 \\ Index Copernicus Value (2013): 6.14 | Impact Factor (2015): 6.391}

the protocol for studying refractive errors in children by Negrel et al, was calculated for a prevalence rate of $22 \%$ for refractive errors with a $20 \%$ error rate and a $95 \%$ confidence interval (CI) and is 340 children. The non-response rate was assumed $10 \%$. Therefore, the calculated sample size for each grade level was 374 children, with a total of 2244 (3 to 9 years old) for all 6 grades. 2199 participated, accounting for a $98 \%$ response rate. Presenting, uncorrected, and bestcorrected visual acuity, along with refractive error under cycloplegia, were the main outcome measures. Children 3 to 5 years of age with a visual acuity of $20 / 40$ or worse and those 6 to 9 years of age with a visual acuity of $20 / 30$ or worse underwent a complete ophthalmic examination to determine the cause of visual impairment. To maintain comparability of our results with those of studies conducted in other parts of the world, the same definitions for refractive errors were used: A spherical equivalent of -0.50 $\mathrm{D}$ or worse for myopia, and $+2.0 \mathrm{D}$ or more for hyperopia. Children with myopia in one or both eyes were classified as myopic, and those with hyperopia in one or both eyes, provided that neither eye was myopic, were classified as hyperopic. For every child, the visual acuity was tested without correction, with correction and, if applicable, with their spectacles. Objective refraction was determined using a Rodenstock autorefractometer. Distance visual acuity was measured with a Snellen retroilluminated $\log$ MAR chart at the distance of $6 \mathrm{~m}$. Strabismus was diagnosed and quantitated with cover testing and observation of the corneal reflex both at 0.5 meters and 4.0 meters (18). Cycloplegic refraction was also checked half an hour after instilling a drop of cyclopentolate $1 \%$ three times with five minute intervals. Children with visual acuity under 20/40 underwent to a complete ophthalmic examination. Astigmatic children were those with a cylinder refraction of $0.75 \mathrm{D}$ or more in at least one eye, which was recorded with a negative sign.

\section{Results and Discussion}

192 (8.7\%) schoolchildren had uncorrected visual acuity $20 / 40$ or worse in the better eye. Prevalence of refractive errors Myopia, Hyperopia and Astigmatism are presented in table 1. Comprehensive comparison of refractive error prevalence across study reports are usually not possible because of different measurement methods and definitions. According to the World Health Organization informal planning meeting, in July 2000 (24). Refractive errors are accountable for more than half of the impaired vision in the majority of surveyed populations(21-23). Variation in the prevalence data from studies in different parts of the world are due to different operational definitions considered by investigators and also due to difference in demographic factors. The prevalence of refractive errors varies according to age, gender, race and geographic location (19). Children from families led by parents with senior levels of educational achievement, and possibly greater possessions may experience more demands for study, entailing near work, which in turn could cause the onset of myopia (20). Myopia was also found to be coupled with time for reading, watching television and playing on a computer (21). It is found that there was a shift in refractive error with age from hyperopia in young children toward myopia in older children. Amblyopia treatment is most effective when done early in the child's life, usually before age 7 (22). School screening is the best way to detect amblyopia in school children. A few children complained of inability to see the black board clearly while some children actually had poor distance vision. This shows that children may not be aware of their problem.

\section{Conclusion}

Visual impairment is a common disorder in schoolaged children, also, affects a large proportion of the population worldwide, irrespective of age, sex, or ethnic group.and refractive error was the main cause of visual impairment. They can be easily diagnosed, measured, and corrected with spectacles and other refractive corrections to obtain normal vision. Unless corrected, they cause low vision and even blindness. As visual impairment can have a significant impact on a child's life in terms of education and development, it is important that effective strategies be developed to eliminate this easily treated cause of visual impairment. Eye health screening programs are beneficial in early detection and proper treatment of refractive error.

\section{References}

[1] Pizzarello L, Abiose A, Ffytche T. et al. Vision 2020: the right to sight: a global initiative to eliminate avoidable blindness. Arch Ophthalmol. 2004;122:615620

[2] He M, Xu J, Yin Q, Ellwein LB. Need and challenges of refractive correction in urban Chinese school children. Optom Vis Sci. 2005;82:229-234

[3] Dandona R, Dandona L. Refractive error blindness. Bull World Health Organ. 2001;79:237-243

[4] Zhan MZ, Saw SM, Hong RZ. et al. Refractive errors in Singapore and Xiamen, China--a comparative study in school children aged 6 to 7 years. Optom Vis Sci. 2000;77:302-308

[5] Arnold RW, Ruben J, Donahue SP, AAPOS Vision Screening Committee. Korean kindergarten vision screen programme. Br J Ophthalmol. 2005;89:392- 393

[6] Zhao J, Pan X, Sui R. et al. Refractive error study in children: Results from Shunyi district, China. Am J Ophthalmol. 2000;129:427-435

[7] Zhao J, Mao J, Luo R, Li F, Munoz SR, Ellwein LB. The progression of refractive error in school-age children: Shunyi District, China. Am J Ophthalmol. 2002;134:735-743

[8] He M, Zeng J, Liu Y, Xu J, Pokharel GP, Ellwein LB. Refractive error and visual impairment in urban children in southern China. Invest Ophthalmol Vis Sci. 2004;45:793-799

[9] Pokharel GP, Negrel AD, Munoz SR, Ellwein LB. Refractive error study in children: results from Mechi Zone, Nepal. Am J Ophthalmol. 2000;129:436444

[10] Goh PP, Abqariyah Y, Pokharel GP, Ellwein LB. Refractive error, and visual impairment in school age children in Gombark district, Malaysia. Ophthalmol. 2005;112:678-685

[11] Dandona R, Dandona L, Srinivas M, Sahare P, Narsaiah S, Muñoz SR, Pokharel GP, Ellwein LB (). Refractive error in children in a rural population in India. Invest Ophthalmol Vis Sci. 2002;4:615-622

\section{Volume 5 Issue 7, July 2016 www.ijsr.net}




\section{International Journal of Science and Research (IJSR) \\ ISSN (Online): 2319-7064}

Index Copernicus Value (2013): 6.14 | Impact Factor (2015): 6.391

[12] Maul E, Barroso S, Munoz SR, Sperduto RD, Ellwein LB. Refractive error study in children: results from La Florida, Chile. Am J Ophthalmol. 2000;129:445-454

[13] National Bureau of Statistics of China. China statistical yearbook 2003 [in Chinese]. Beijing: China Statistics Press. 2003:100-102

[14] Negrel AD, Maul E, Pokharel GP, Zhao J, Ellwein LB. Refractive error study in children: sampling and measurement methods for a multi-country survey. Am J Ophthalmol. 2000;129:421-426

[15] Ojaimi E, Rose KA, Morgan IG. et al. Distribution of ocular biometric parameters and refraction in a population-based study of Australian children. Invest Ophthalmol Vis Sci. 2005;46:2748-2754

[16] Anera RG, Soler M, de la Cruz Cardona J, Salas C, Ortiz C. Prevalence of refractive errors in school-age children in Morocco. Clinical and Experimental Ophthalmology. 2009;37:191-196

[17] Robaei D, Kifley A, Rose KA, Mitchell P. Refractive error and patterns of spectacle use in 12-year-old Australian children. Ophthalmology. 2006;113:15671573

[18] Saw SM, Chua WH, Hong CY. et al. Nearwork in early-onset myopia. Invest Ophthalmol Vis Sci. 2002;43:332-339

[19] Saw SM, Hong RZ, Zhang MZ. et al. Near-work activity and myopia in rural and urban schoolchildren in China. J Pediatr Ophthalmol Strabismus. 2001;38:149155

[20] Mutti DO, Mitchell GL, Moeschberger ML, Jones LA, Zadnik K. Parental myopia, near work, school achievement, and children's refractive error. Invest Ophthalmol Vis Sci. 2002;43:3633-3640

[21] Erdurmus M, Yagci R, Karadag R, Durmus M. A comparison of photorefraction and retinoscopy in children. J AAPOS. 2007;11:606-611

[22] Rose KA, Morgan IG, Ip J. et al. Outdoor activity reduces the prevalence of myopia in children. Ophthalmology. 2008;15:1279-1285

Table 1: Prevalence of refractive errors

\begin{tabular}{|c|c|c|c|}
\hline Type & $\begin{array}{c}\text { Myopia } \\
\mathrm{N}(\%)(95 \% \mathrm{CI})\end{array}$ & $\begin{array}{c}\text { Hyperopia } \\
\mathrm{N}(\%)(95 \% \mathrm{CI})\end{array}$ & $\begin{array}{c}\text { Astigmatism } \\
\mathrm{N}(\%)(95 \% \mathrm{CI})\end{array}$ \\
\hline All & 1.5 & 1.2 & 2.5 \\
& $1.1-2.1$ & $0.8-1.7$ & $1.9-3.2$ \\
\hline Among cases & & & \\
\hline Male & 0.5 & 0.6 & 1.4 \\
& $0.3-0.9$ & $0.3-1.2$ & $0.9-1.9$ \\
\hline Female & 0.9 & 0.6 & 1.0 \\
& $0.6-1.4$ & $0.3-1.2$ & $0.6-1.5$ \\
\hline $3-6 \mathrm{yr}$ & 0.5 & 1.0 & 0.9 \\
& $0.3-0.9$ & $0.6-1.5$ & $0.6-1.4$ \\
\hline $7-9 \mathrm{yr}$ & 1.0 & 0.3 & 1.3 \\
& $0.6-1.5$ & $0.1-0.6$ & $0.9-1.9$ \\
\hline
\end{tabular}

Volume 5 Issue 7, July 2016 www.ijsr.net 